\title{
Evaluation of patients with COVID-19 diagnosis for chronic diseases
}

\author{
Murat Altuntas $^{1 *} \mathbb{0}$, Habip Yilmaz ${ }^{2}$ and Abdullah Emre Guner ${ }^{2}$
}

\begin{abstract}
Aim: COVID-19 is one of the most consequential pandemic in world history. Chronic diseases, which are risk factors that increase the case fatality rates, have been the leading cause of death all over the world. This study was aimed at detecting coexisting chronic diseases in patients hospitalized with a diagnosis of COVID-19.

Material and method: The study was carried out with data from 229 patients in an intensive care unit, from June 1st through June 30th. 2020. The inclusion criteria of the study was as follows: (1) having a COVID-19 diagnosis confirmed by PCR test; (2) being hospitalized in the relevant intensive care unit within the dates of the study; and (3) having their data accessible through the hospital automation system. Through literature; chronic diseases of the patients and their effects on the COVID-19 process were evaluated. Statistical analyzes were performed using the Statistical Package for Social Sciences (SPSS) version 24.0 (IBM Corp.; Armonk, NY, USA).

Results: The average age of the patients studied were 61.4 years. While the average symptom duration was 8.2 days; total hospitalization period was 13.1 days. The average length of stay of patients $(n=75)$ who were sent to intensive care unit was 10.1. The most common chronic disease among patients was hypertension with $47.2 \%$. This was followed by diabetes mellitus (32.8\%) and heart disease (27.5\%), respectively. In the population studied, cough (59.4\%), fever (58.5\%) and shortness of breath (45.9\%) were found to be the most common symptoms. Leukopenia, impairments in liver and muscle enzymes, abnormal C-reactive protein, ferritin and d-dimer levels were the important biochemical tests.
\end{abstract}

Conclusion: Particular attention should be paid to the elderly COVID-19 patients with chronic diseases, especially DM, HT and cancer.

Keywords: Chronic disease, COVID-19, Diagnosis, Patient

\section{Introduction}

December of 2019, a new severe acute respiratory syndrome, COVID-19, was reported in Wuhan, China. The virus causing this airborne disease was determined to be coronavirus-2 (SARS-CoV-2) [1]. COVID-19 is the largest pandemic in the world after H1N1 influenza epidemic in 1918 [2]. Based on the current studies the clinical course of the disease varies from mild upper respiratory

*Correspondence: murataltuntas@yahoo.com

${ }^{1}$ University of Health Sciences Bagcilar Training and Research Hospital, Istanbul, Turkey

Full list of author information is available at the end of the article tract infection findings to severe viral pneumonia accompanied by loss of taste and smell and respiratory failure [3].

Although the virus infects individuals of all ages; it is known that people at an older age and with concomitant chronic diseases have more severe symptoms. Studies show that among the the increasing number of cases mostly affected populations are people with previously known chronic diseases [4]. Risk factors associated with serious disease and mortality are advanced age, cardiovascular disease (CVD), diabetes mellitus (DM), hypertension (HT), chronic lung disease, cancers, chronic kidney disease (CKD), use of immunosuppressive or 
biological agents, obesity, and smoking [5]. These diseases, which are risk factors that increase the case fatality rates, have been the leading cause of death in all developed or developing countries around the world [6].

Chronic diseases affect mortality with different mechanisms during COVID-19. It is known that there is an increase in troponin level associated with disease severity and mortality during the course of the disease. Severe viral infections causing systemic inflammatory syndrome increase the risk of plaque, rupture and thrombus formation, and thus result in cardiovascular events [7]. In the course of COVID-19, microangiopathic changes occurring in the respiratory tract of diabetic patients reduce gas exchange and lung compliance and cause a significant decrease in forced vital capacity (FVC) and forced expiratory volume in 1.second (FEV1) [8]. Hypertension is another important disease that need to be placed attention in Covid patients. SARS-CoV-2 enters target cells by binding to angiotensin converting enzyme 2 (ACE2) expressed on epithelial cells of lung, kidney, blood vessels. ACE2 expression increases in patients with HT and $\mathrm{DM}$, who are treated with ACE inhibitors or receptor blockers [9].

It is known that the rates of chronic diseases are also high in regions with high mortality rates such as China, Europe, and the United States [10]. Identifying additional risk factors associated with COVID-19 patients will also affect the survival of individuals in this group. In this study, it is aimed to detect coexisting diseases in patients hospitalized with the diagnosis of COVID-19.

\section{Material and method}

The study was carried out in Health Sciences University Bağcllar Training and Research Hospital Adult Intensive Care Unit, from June 1st through June 30th. 2020. It is a prospective, cross-sectional study. Study participants were selected based on the following criteria; (1) to have a diagnosis confirmed by Polymerase Chain Reaction (PCR) test, (2) to be hospitalized in the relevant intensive care unit on the date of the study and (3) to have data accessible through the hospital automation system. A total of 229 patients who have these criteria were included in the study.

Study was approved by the Ethics Committee of Istanbul Göztepe Training and Research Hospital, Turkey with the decision number 2020/0243. In addition; TR Ministry of Health Scientific Research Platform on COVID-19 has also obtained a work permit with the date 04.05.2020 and number T190535.

Statistical analysis was performed by IBM SPSS Statistics 24 program. Descriptive data are presented by giving percentage distributions and mean \pm standard deviation. T-test was used for measurement data in independent groups and Pearson chi-square test was used for census data in examining causality relationships. Considering the 95\% confidence interval and 5\% margin of error in the analysis, $p<0.05$ was accepted as a significance level.

\section{Results}

Total 75 patients $(32.8 \%)$ of the study group were female and $154(67.2 \%)$ were male. It was seen that the average age of the patients was 61.4 years old. While the average symptom duration was 8.2 days; total hospitalization period was 13.1 days. The average length of stay of 75 patients who were sent to intensive care unit was determined as 10.1 .

The most common chronic disease among patients was hypertension with $47.2 \%$. This was followed by diabetes mellitus (32.8\%) and heart disease (27.5\%), respectively. The distribution of patients according to their chronic diseases was given in Fig. 1.

Distribution of the COVID-19 inpatients according to their symptoms and the treatments they received; was presented in Table 1.

According to the symptom distribution of the patients; it was observed that cough, fever and shortness of breath were observed with close frequency. Among the symptoms of fever, cough, shortness of breath and runny nose, the least common symptom was runny nose with $2.2 \%$. Considering the distribution of the disease according to its clinical severity; it was seen that the most common clinical presentation was "moderate" (50.7\%). While all patients $(100 \%)$ recieved the favipiravir treatment, only $14.8 \%$ of the patients recieved corticosteroid treatment. When the treatment results of the patients examined, it is observed that $59.5 \%$ were still hospitalized during the period data were collected, and $24 \%$ died. Biochemical

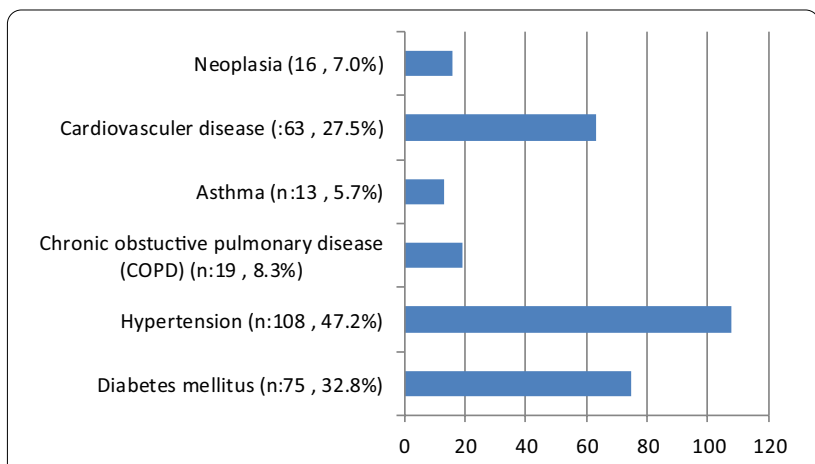

Fig. 1 Distribution of the patients according to their chronic

diseases. ${ }^{*}$ Those with more than one registered disease at the same time in the automation system were included in all groups separately 
Table 1 Distribution of the patients according to their symptoms and medications

\begin{tabular}{lrr}
\hline & $N^{a}$ & $\%$ \\
\hline Fever & 134 & 58.5 \\
Cough & 136 & 59.4 \\
Shortness of breath & 105 & 45.9 \\
Runny nose & 5 & 2.2 \\
Clinic & & \\
Mild & 1 & 0.4 \\
Moderate & 116 & 50.7 \\
Bad & 21 & 9.2 \\
Terrible & 91 & 39.7 \\
Intensive care admission & 93 & 40.6 \\
Oseltamivir treatment & 154 & 67.2 \\
Favipiravir treatment & 229 & 100.0 \\
Combined therapy & 101 & 44.1 \\
Vitamin C & 117 & 51.1 \\
Cortikosteroid & 34 & 14.8 \\
Anticoagulant therapy & 192 & 83.8 \\
Mechanical ventilation & 67 & 29.3 \\
Result (n=227) & & \\
Exitus & 55 & 24.0 \\
Hospitalization continues & 135 & 59.5 \\
Admission to intensive care & 32 & 14.0 \\
Hospitalization in another service & 1 & 0.4 \\
\hline
\end{tabular}

${ }^{a}$ Those with more than one registered disease at the same time in the automation system were included in all groups separately

values of patients during initial hospitalization are presented in Table 2.

After the analysis of post descriptive data, causality comparisons were performed. Causality comparisons were conducted based on gender and chronic diseases.

\section{Causality comparisons by gender}

When the distribution of chronic diseases by gender was examined; DM, HT and asthma were significantly higher in females than males (respectively; $\mathrm{x}^{2}=6.407, p$ : 0.016; $\chi^{2}=7.370, p: 0.007$; Fisher's $\left.p: 0.011\right)$. Chronic obstructive pulmonary disease $(\mathrm{COPD})$ is significantly higher in men than women $\left(x^{2}=4.647, p: 0.031\right)$.

When the distribution by gender is examined in terms of the severity of the clinical picture and prognosis; there was no significant difference between the two sexes $\left(\chi^{2}=2.396, p: 0.494 ; \chi^{2}=3.242, p: 0.198\right.$, respectively $)$. When the results of the patient treatment were examined according to gender, no significant difference was found $\left(\chi^{2}=4.034, p: 0.401\right)$. In addition, when disease symptoms were examined by gender, no significant difference was found in terms of fever, cough, shortness of breath and nasal discharge $\left(\chi^{2}=1.950, p: 0.163 ; \chi^{2}=0.195, p\right.$ : $0.659 ; \chi^{2}=0.154, p: 0.695$; Fisher's $p: 0.695$, respectively).

$\mathrm{T}$ test analysis of age distribution by gender; revealed that women are significantly older than men ( $\mathrm{t}$ test $p$ : 0.007). Hospitalization C-reactive protein (CRP) value was found to be significantly higher in men than women ( t test: $p$ : 0.001).

\section{Causality comparisons according to chronic diseases}

When the symptoms of fever, cough, shortness of breath and runny nose are examined according to chronic diseases; there was no difference in the presence of DM, COPD, neoplasia. Those with HT are found to be significantly higher than those without fever $\left(x^{2}=4.850\right.$, $p$ : 0.028). Patients with asthma were found significantly more likely to present shortness of breath than the others $\left(\chi^{2}=8.341, p: 0.004\right)$. The patients with heart disease were significantly higher in presenting cough and shortness of breath than those without the disease $\left(\chi^{2}=4.992\right.$, $p: 0.025 ; \chi^{2}=4.463, p: 0.035$, respectively).

Considering the clinical picture of patients with DM, the rate of bad and severe cases were found significantly higher than those without $\operatorname{DM}\left(\chi^{2}=10.466, p\right.$ : 0.015). Similarly, the rates of admission to intensive care unit

Table 2 Summary of biochemical investigations in hospitalized COVID-19 patients

\begin{tabular}{|c|c|c|c|c|c|}
\hline & $\mathrm{N}$ & Minimum & Maximum & Average & Std. deviation \\
\hline Leukocyte & 228 & 830.0 & $59,770.0$ & 8036.7 & 5571.9 \\
\hline BUN & 227 & 13.0 & 244.1 & 44.6 & 32.6 \\
\hline Creatinin & 210 & .3 & 10.3 & 1.3 & 1.2 \\
\hline Aspartat aminotransferaz (AST) & 229 & 9.0 & 2028.0 & 47.5 & 134.9 \\
\hline Alanin aminotransferaz (ALT) & 229 & 6.0 & 561.0 & 38.6 & 45.2 \\
\hline C-reaktif protein (CRP) & 219 & .01 & 318.4 & 87.1 & 73.4 \\
\hline Procalcitonin & 107 & .01 & 20.0 & 1.4 & 3.5 \\
\hline Ferritin & 154 & 13.0 & $36,872.5$ & 925.6 & 3107.0 \\
\hline D-dimer & 209 & 0.01 & 27.7 & 1.2 & 2.5 \\
\hline
\end{tabular}


and exitus were higher in this patient group $\left(\chi^{2}=7.584\right.$, $p$ : 0.006; $\chi^{2}=10.367, p$ : 0.035).

There were no significant differences found in clinical picture and outcome of patients with HT. The rates of admission to intensive care unit were higher in this patient group than those who don't have HT $\left(\chi^{2}=6.069\right.$, $p$ : 0.014).

No significant difference were found between those with and without COPD and asthma in terms of clinical picture, prognosis, admission to intensive care and outcome compared to those without COPD.

When compared with those without heart disease, those with heart disease admitted to intensive care were higher (for ICU admission $\chi^{2}=6.429, p$ : 0.011).

When patients with neoplasia and those without neoplasia are compared; it was seen that the clinical picture was significantly worse in patients with neoplasia than those without neoplasia $\left(\chi^{2}=16.721, p: 0.001\right)$. It was also found that the rate of exitus in patients with neoplasia was significantly higher than in those without neoplasia $\left(x^{2}=16.147, p: 0.003\right)$.

\section{Cross comparisons of chronic diseases and biochemical tests}

While blood urea nitrogen (BUN) and CRP were found to be significantly higher in DM patients than those without DM, the duration of symptoms was shorter ( $\mathrm{t}$ test: $p$ : $0.0001, p: 0.001, p: 0.042, p: 0.005$, respectively).

While BUN, procalcitonin and d-dimer were found to be significantly higher in patients with HT than those without HT, the symptom duration was shorter (t test: $p: 0.0001, p: 0.001, p: 0.0001, p: 0.007, p: 0.008$, respectively).

Age, CRP, and total length of stay were significantly higher in patients with COPD than those without $(\mathrm{t}$ test: $p: 0.001, p: 0.009, p: 0.007$, respectively). Symptoms and duration of intensive care were found to be lower in patients with asthma compared to those without intensive care (t test: $p: 0.011, p: 0.036$, respectively). There was no significant difference for the others.

Age, BUN, creatinine and non-d-dimer were significantly higher in those with heart disease than those without. The symptom duration was lower (t test: $p: 0.0001, p$ : $0.0001, p: 0.035, p: 0.004, p: 0.015$, respectively).

\section{Discussion}

In the studies conducted in different countries during the first period of the global epidemia, it was found that most of the patients were male and advanced age [11-13]. In one of the first studies on this field conducted in Wuhan, it was reported that the patients were mostly composed of elderly women and the most important diseases associated were hypertension, diabetes, heart diseases and
COPD [14]. In this study similar results were observed in age and gender (male ratio 67.2\%, mean age 61.4 \pm 15.9 ).

Hypertension was found to be the most common chronic disease associated with patients diagnosed with COVID-19 in the study (47.2\%). High risk of serious disease in hypertensive patients was thought to be related; with the use of angiotensin converting enzyme 2 (ACE2) as the viral entry receptor in lung cells by the virus, with the high prevalence of hypertension in the population, and the frequency of use of renin-angiotensin system (RAS) blockers [14]. In the study, although fever in these patients is statistically significantly higher than other symptoms, the mechanism of this is not fully known. In different studies, it is emphasized that hypertension is a common comorbidity for COVID-19 infection, which significantly affects mortality and disease severity $[11,12$, $15,16]$.

The frequency of diabetes mellitus in the study was found to be $32.8 \%$. With this rate, diabetes is the second most common disorder among the patients who participated in the study. For diabetes mellitus, Huang et al. reported as the main comorbidity disease with a frequency of $20 \%$ [11]. Its' frequency was found around $10 \%$ in different studies [17].

Cardiovascular diseases were found to be the third most common chronic disease in the study group (27.5\%). Case series with additional cardiovascular disease have also been reported in the literature $[18,19]$.

Although the disease affects the respiratory tract; Huang et al. [11] and Wang et al. [18] found the prevalence of accompanying COPD to be $2 \%$ and $2.9 \%$, respectively. Similarly, Chen et al. [19] found associated respiratory system diseases $1 \%$ in their study. In the study, COPD was seen at a very high rate with $8.3 \%$ and asthma $5.7 \%$. These high rates found in the study have been associated with the high frequency of respiratory system diseases. In addition, rare, bronchiectasis, interstitial lung disease and tobacco use have been reported as coexisting risk factors alone [12, 13, 20, 21]. Moreover; in patients with asthma, the statistically significant excess of shortness of breath was associated with the clinical course of the disease.

Advanced DM, HT, neoplasia and heart disease patients with COVID-19 required significantly more intensive care. There was no statisticly significant relationship found between the need for intensive care and the severity of the disease with COPD. This finding might be contributed to the size of the population studied, and we recommend caution in interpreting this finding. We recommend more studies conducted to detremine the relationship between the need for intensive care and the severity of the disease with COPD. 
Neurological diseases are the disease group that cause the highest health burden especially in the elderly population [22]. Despite this, no neurological disease was found in the records of patients diagnosed with COVID19 in the study. Considering that neurological diseases require long-term follow-up and treatment; even if there is no COVID-19 diagnosis, special attention should be paid to the follow-up of these patients.

In present study, no findings regarding with digestive system disorders and COVID-19 were found. However; it has been reported that some patients with COVID19 show digestive symptoms such as diarrhea, vomiting and abdominal pain, and the average liver enzyme levels of these patients were also high [23]. Although it has been stated that inflammatory bowel diseases such as Crohn's and colitis ulcerosa may be diseases in patients with COVID-19 that contribute as genetic predisposition and environmental factors [24], no findings were found in this study. This finding might be attributed to the study group in the intensive care unit, and this finding need to be interpreted cautiously.

Cough (59.4\%), fever (58.5\%) and shortness of breath (45.9\%) were found to be the most common symptoms in this study. This situation was parallel to the literature [3, $19,21]$.

In the conducted studies, leukopenia is the most common laboratory finding; rarely, thrombocytopenia is observed [3, 12, 25]. In the literature, impairments have also been reported in liver and muscle enzymes. Abnormal elevations can also be observed in C-reactive protein, ferritin and d-dimer levels [16, 17].

\section{Conclusion}

It would be appropriate to evaluate carefully to COVID19 patients, especially for the current chronic diseases. Particular attention should be paid to the elderly COVID19 patients with chronic diseases, especially DM, HT and cancer.

\section{Abbreviations}

ACE-2: Angiotensin converting enzyme-2; BUN: Blood urea nitrogen; CKD: Chronic kidney disease; COPD: Chronic obstructive pulmonary disease; CRP: C-Reactive protein; COVID-19: Severe acute respiratory syndrome 2, SARS-2; CVD: Cardiovascular disease; DM: Diabetes mellitus; FEV-1: Forced expiratory volume in $1 \mathrm{~s}$; FVC: Forced vital capacity; HT: Hypertension; ICU: Intensive care unit; PCR: Polymerase chain reaction; RAS: Renin angioensin system; SPSS: Statistical package for social sciences.
\end{abstract}

\section{Authors' contributions}

MA: Drafting the work, substantial contributions to the conception of the work, acquisition, analyses, final approval of the version to be published. HY: Collected the data, final approval of the version to be published. AEG: Final approval of the version to be published. All authors read and approved the final manuscript.
Funding

There is no any private funding used. Funding has been covered by authors.

Availability of data and materials

Not applicable.

\section{Declarations}

\section{Ethics approval and consent to participate}

It was approved by the Ethics Committee of Istanbul Göztepe Training and Research Hospital with the decision number 2020/0243. In addition; TR Ministry of Health Scientific Research Platform on COVID-19 has also obtained a work permit with the date 04.05.2020 and number T190535.

\section{Consent to publication}

Not applicable.

\section{Competing interests}

There is no financial or non-financial conflict of interest.

\section{Author details}

${ }^{1}$ University of Health Sciences Bagcilar Training and Research Hospital, Istanbul, Turkey. ${ }^{2}$ Provincial Health Directorate, Istanbul, Turkey.

Received: 16 December 2020 Accepted: 4 March 2021

Published online: 17 March 2021

\section{References}

1. http://www.euro.who.int/en/health-topics/health-emergencies/coron avirus-covid-19/news/news/2020/3/who-announces-covid-19-outbr eak-a-pandemic. 30 March 2020.

2. Moein ST, Hashemian SMR, Mansourafshar B, Tousi AK, Tabarsi P, Doty RL. Smell dysfunction: a biomarker for COVID-19. Int Forum Allergy Rhinol. 2020;10(8):944-50.

3. Zhu N, Zhang D, Wang W, Li X, Yang B, Song J, et al. China Novel Coronavirus Investigating and Research Team. A novel coronavirus from patients with pneumonia in China, 2019. N Engl J Med. 2020;382:727-33.

4. Ssentongo P, Ssentongo AE, Heilbrunn ES, Ba DM, Chinchilli VM. Association of cardiovascular disease and 10 other pre-existing comorbidities with COVID-19 mortality: a systematic review and meta-analysis. PLoS ONE. 2020;15(8):e0238215.

5. Zhou F, Yu T, Du R, et al. Clinical course and risk factors for mortality of adult inpatients with COVID-19 in Wuhan, China: a retrospective cohort study. Lancet. 2020;395(10229):1054-62.

6. Organization WH. Noncommunicable diseases. https://www.who.int/ news-room/fact-sheets/detail/noncommunicable-diseases.

7. Kang Y, Chen T, Mui D, Ferrari V, Jagasia D, Scherrer-Cros-bie M, et al. Cardiovascular manifestations and treatment considerations in COVID-19. Heart. 2020;106(15):1132-41.

8. Hussain A, Bhowmik B, do Vale Moreira NC. COVID-19 and diabetes: knowledge in progress. Diabetes Res Clin Pract. 2020;162:108142.

9. Wan Y, Shang J, Graham R, Baric RS, Li F. Receptor recognition by the novel coronavirus from Wuhan: an analysis based on decade-long structural studies of SARS coronavirus. J Virol. 2020;94(7):e00127-e220.

10. Yusuf S, Joseph P, Rangarajan S, Islam S, Mente A, Hystad P, et al. Modifiable risk factors, cardiovascular disease, and mortality in 155722 individuals from 21 high-income, middle-income, and low-income countries (PURE): a prospective cohort study. The Lancet. 2020;395(10226):795-808.

11. Huang $C$, Wang $Y, L i X$, Ren $L$, Zhao J, Hu Y. Clinical features of patients infected with 2019 novel coronavirus in Wuhan, China. Lancet. 2020;395:497-506.

12. Rothe C, Schunk M, Sothmann P, Bretzel G, Froeschl G, Wallrauch C. Transmission of 2019-nCoV infection from an asymptomatic contact in Germany. N Engl J Med. 2020;382:970-1.

13. Holshue ML, DeBolt C, Lindquist S, Lofy KH, Wiesman J, Bruce H. First case of 2019 novel coronavirus in the United States. N Engl J Med. 2020;382:929-36. 
14. Lian J, Jin X, Hao S, Cai H, Zhang S, Zheng L. Analysis of epidemiological and clinical features in older patients with corona virus disease 2019 (COVID-19) out of Wuhan. Clin Infect Dis. 2020;71(15):740-7.

15. Kreutz R, Algharably EAE, Azizi M, Dobrowolski P, Guzik T, Januszewicz A, et al. Hypertension, the renin-angiotensin system, and the risk of lower respiratory tract infections and lung injury: Implications for COVID-19. Cardiovasc Res. 2020;116(10):1688-99.

16. Taşkaldıran I, Bayraktaroğlu T. COVID-19 ve hipertansiyon. Türkiye Diyabet ve Obezite Dergisi. 2020;2:155-9.

17. Lui K, Fang YY, Deng Y, Liu W, Wang MF, Ma JP. Clinical characteristics of novel coronavirus cases in tertiary hospitals in Hubei Province. Chin Med J. 2020;133(9):1025-31.

18. Wang D, Hu B, Hu C, Zhu F, Liu X, Zhang J. Clinical characteristics of 138 hospitalized patients with 2019 novel coronavirus-infected pneumonia in Wuhan, China. JAMA. 2020;323(11):1061-9.

19. Chen N, Zhou M, Dong X, Qu J, Gong F, Han Y. Epidemiological and clinical characteristics of 99 cases of 2019 novel coronavirus pneumonia in Wuhan, China: a descriptive study. Lancet. 2020;395:507-13.

20. Lei J, Li J, Li X, Qi X. CT imaging of the 2019 novel coronavirus (2019nCoV) pneumonia. Radiology. 2020;295(1):18.
21. Li Q, Guan X, Wu P, Wang X, Zhou L, Tong Y, et al. Early transmission dynamics in Wuhan, China, of novel coronavirus-infected pneumonia. N Engl J Med. 2020;382(13):1199-207.

22. Öztürk S. COVID-19 and neurology. Turk J Neurol. 2020;26(2):109-11.

23. Durmaz A. SARS-CoV2 ve COVID-19'a genel bakış. Smyrna Tıp Dergisi. 2020;10(3):60-70

24. Monteleone G, Ardizzone S. Are patients with inflammatory bowel disease at increased risk for COVID-19 infection ? J Crohns Colitis. 2020;14(9):1334-6.

25. Ren LL, Wang YM, Wu ZQ, Xiang ZC, Guo L, Xu T, et al. Identification of a novel coronavirus causing severe pneumonia in human: a descriptive study. Chin Med J. 2020;133(9):1015-24.

\section{Publisher's Note}

Springer Nature remains neutral with regard to jurisdictional claims in published maps and institutional affiliations.
Ready to submit your research? Choose BMC and benefit from:

- fast, convenient online submission

- thorough peer review by experienced researchers in your field

- rapid publication on acceptance

- support for research data, including large and complex data types

- gold Open Access which fosters wider collaboration and increased citations

- maximum visibility for your research: over $100 \mathrm{M}$ website views per year

At BMC, research is always in progress.

Learn more biomedcentral.com/submissions 